\title{
La locura trágica: el caso de las tragedias fragmentarias de Eurípides sobre el mito de Alcmeón ${ }^{1}$
}

\author{
Cecilia J. Perczyk ${ }^{2}$
}

Recibido: 4 de Junio de 2020 / Aceptado: 20 de Julio de 2020

Resumen. En el presente trabajo me propongo analizar la representación de la locura en las dos tragedias fragmentarias que Eurípides dedicó a la saga de Alcmeón. Aun cuando los fragmentos conservados no tratan los ataques de manía del protagonista, es posible aportar al estudio de la enfermedad a partir de los datos ofrecidos sobre el origen y las consecuencias, en especial sobre el crimen asociado, que es el matricidio. Se interpretarán los fragmentos conservados a la luz de otras fuentes sobre el mismo mito y la tragedia que Eurípides dedicó a la locura de Orestes, debido a los puntos en común que tienen las dos sagas.

Palabras clave: Alcmeón, Tragedia fragmentaria, Eurípides, locura.

\section{[en] The tragic madness: the case of Euripides' fragmentary tragedies on the myth of Alcmeon}

\begin{abstract}
In the present work, I intend to analyze the representation of madness in the two fragmentary tragedies that Euripides dedicated to the Alcmeon saga. Although the fragments preserved do not treat the maniac attacks of the main character, it is possible to contribute to the study of the illness from the data offered about the origin and consequences, especially about the associated crime, which is the matricide. It will be interpreted the fragments preserved in the light of other sources about the same myth and the tragedy that Euripides dedicated to Orestes' madness, due to the points in common between the two sagas.
\end{abstract}

Keywords: Alcmaeon, fragmentary tragedy, Euripides, madness.

Sumario. 1. Introducción. 2. Observaciones preliminares. 3. Datos generales sobre Alcmeón en Psófide y Alcmeón en Corinto. 4. Alcmeón y Orestes. 5. El míasma. 6. Conclusiones.

Cómo citar: Perczyk, C. J. (2021), La locura trágica: el caso de las tragedias fragmentarias de Eurípides sobre el mito de Alcmeón, en Cuadernos de Filología Clásica. Estudios griegos e indoeuropeos 31, $35-54$.

1 El presente artículo fue realizado en el marco del Proyecto PICT de Agencia Nacional de Promoción Científica y Tecnológica (convocatoria 2017-2019, Fondo para la Investigación Científica y Tecnológica) "Locura, emoción y crimen en el corpus fragmentario de la tragedia griega clásica” (Instituto de Filología Clásica, Facultad de Filosofía y Letras, Universidad de Buenos Aires).

2 Universidad Nacional de Hurlingham (Villa Tesei, Buenos Aires), Instituto de Educación; Universidad Nacional de San Martín, Escuela de Humanidades; Universidad de Buenos Aires, Facultad de Filosofía y Letras, Instituto de Filología Clásica, que dirijo. cecilia.perczyk@unahur.edu.ar 


\section{Introducción}

En el marco de la indagación sobre la relación del hombre con la divinidad y con su propia psykhé, aspectos determinantes del género trágico, la locura de los héroes es una de las formas elegidas por los poetas para expresar dicha búsqueda ${ }^{3}$. Entre las obras conservadas de forma completa, nos encontramos con que en gran parte de los casos se relaciona la enfermedad con un crimen intrafamiliar. Los casos de locura asesina tienen particularidades que los separan de otras modalidades, como la manía erótica o la profética. Así Orestes (en Coéforas de Esquilo, en Orestes e Ifigenia entre los tauros de Eurípides), Áyax (en Áyax de Sófocles), Heracles (en Heracles de Eurípides), Ágave (en Bacantes de Eurípides) exhiben manifestaciones de la manía y cometen, o creen cometer, el homicidio de un phílos, ya sea como causa o consecuencia de la enfermedad.

Ahora bien, el estudio sobre la locura asesina no se agota en las tragedias completas sino que, por el contrario, muchas de las obras fragmentarias de los tres trágicos también escenifican esta patología en distintos héroes y el crimen vinculado a la afección ${ }^{4}$. Tenemos, entre ellos, la figura de Alcmeón, un héroe famoso de la Grecia

3 Para un estudio sobre la locura en el género trágico consúltese Padel (2005 [1995]), que no incluye en el análisis las tragedias fragmentarias sobre el mito Alcmeón, pero sí menciona las de Atamante y Licurgo (Padel 2005 [1995]: 63, 74-75, 219, 254 y 355). Para Padel (2005 [1995]: 74-76) la manía en las obras de los tres trágicos constituye un estado temporario, agudo y visible, cuya causa es externa. Conti Jiménez (2000: 42) señala que el motivo trágico de la locura como castigo divino, ausente en Homero, constituye un instrumento que permite indagar el perfil humano y las relaciones del hombre con la divinidad. Además, destaca una serie de coincidencias entre las descripciones de la conducta de los personajes de Ayax, Heracles, Orestes y Bacantes con los síntomas de los pacientes en los tratados hipocráticos, especialmente Sobre la enfermedad sagrada (Conti Jiménez 2000: 45-48). En tanto, Caballero González (2011: 1272), en su estudio sobre el personaje de Atamante en las literaturas griega y latina, sigue a Padel con su idea de que la locura trágica es un arrebato temporal, viene de fuera y es causada por los dioses. Diferencia entre dos tipos de locura: la violenta, como la de Atamante, inducida para que se lleve a cabo un asesinato por medio de ella, y la punitiva, como la de Orestes, provocada como castigo por un delito cometido (Caballero González 2011: 1272). Por mi parte, me distancio de los autores antes citados, específicamente respecto de Eurípides, en tanto, al estudiar las tragedias Heracles, Orestes y Bacantes, identifiqué, en primer lugar, una continuidad entre la conducta de los héroes antes y después de los ataques de locura, por lo que entiendo que no se trata de un estado temporario (Perczyk 2018a: 195-242, y Perczyk 2018b: 46 y 60-62). En segundo lugar, reconocí una serie de paralelos entre la representación de la locura en las obras mencionadas de Eurípides y la concepción propuesta por la medicina hipocrática sobre los trastornos que hoy denominamos mentales en los cuadros descritos en los tratados Sobre la enfermedad sagrada y Sobre las enfermedades de las vírgenes que excede la coincidencia léxica en la descripción de los síntomas (Perczyk 2017, y Perczyk 2018a: 72-91). Véase al respecto Holmes (2010), que demuestra que la configuración del cuerpo como objeto epistémico en el siglo V a.C. depende del desarrollo de la medicina hipocrática y de la emergencia en simultáneo del síntoma en el género trágico. Si bien las conclusiones alcanzadas respecto de Heracles, Orestes y Bacantes no son inmediatamente trasladables a los fragmentos conservados de Eurípides sobre el mito de Alcmeón, porque en los fragmentos conservados no hay datos explícitos sobre los ataques de locura del protagonista, parto para su análisis de la idea de que el trágico se apropia de la concepción tradicional de la locura para afrontar inquietudes propias de la Atenas clásica, en el sentido de restringir la participación divina en los asuntos humanos, otorgar responsabilidades a los personajes acerca de sus actos, indicar un origen hereditario para la enfermedad y adjudicar al lógos un papel central en la recuperación del enfermo.

$4 \quad$ En las tragedias fragmentarias de los tres trágicos, la manía golpea a los siguientes personajes: a Licurgo, en la tetralogía que Esquilo le dedica (compuesta por Edonos, Básarides, Los muchachos y Licurgo), que mata a su hijo confundiéndolo con un sarmiento (fr. 23-25, 57-67, 123b-126 y 146-19 Radt, 1985: 138-140, 178-185, 234-236 y 259-261, y Lucas de Dios 2008: 179-182, 280-282 y 298-300); a Ixión, en Las mujeres de Prerrebia de Esquilo (fr. 184-186b Radt, 1985: 300-301, y Lucas de Dios 2008: 338-339); a Atamante e Ino, que asesinan a sus hijos, de nombre Learco y Melicertes, en las tragedias de Esquilo y Sófocles, ambas llamadas Atamante (fr. 1-4a Radt, 1985: 123-125; fr. 1-10 Radt, 1999 [1975]: 99-102, y Lucas de Dios 1983: 32-34 y 2008: 138-141), y en Ino de Eurípides (fr. 398-423 Kannicht, 2004: 442-455); a Télefo, en Aléadas de Sófocles, que asesina a 
antigua que mató a su madre y padeció ataques de locura, pero de quien, por el azar de la tradición literaria, no nos han llegado de forma completa ni los poemas épicos ni las tragedias que lo cuentan entre sus personajes ${ }^{5}$.

En el presente trabajo me propongo estudiar la representación de la locura en las tragedias conservadas de forma fragmentaria que Eurípides dedicó a la saga de este matricida, Alcmeón en Psófide y Alcmeón en Corinto. Aunque los fragmentos no tratan los episodios de manía del héroe, cuya existencia conocemos por otras fuentes, es posible a partir de estos estudiar aspectos fundamentales de la representación trágica de la locura, como el crimen asociado, el matricidio, y su consecuencia directa, el míasma. Para lo cual analizaré de forma comparativa los fragmentos con la tragedia que Eurípides dedica al mito de Orestes y su enfermedad, debido a los puntos en común que tienen ambos mitos. Además, se tomarán en cuenta dramas de autores posteriores, específicamente los de los poetas trágicos latinos, que reelaboraron la saga de Alcmeón, y se indicarán alusiones en otras obras clásicas a los personajes de la misma saga.

\section{Observaciones preliminares}

De las dos tragedias que Eurípides dedicó a la figura de Alcmeón se han conservado fragmentos papiráceos y de transmisión indirecta ${ }^{6}$. Sabemos que las dos obras circularon, en principio, con el mismo nombre hasta que los alejandrinos en el siglo II a.C. añadieron los títulos suplementarios (Collard \& Cropp 2008: 77). El hecho de que en los testimonios suele hacerse referencia a ambas tragedias con el nombre Alcmeón constituye obviamente un problema, ya que no es posible diferenciar a cuál de las piezas compuestas por el trágico pertenecen. La situación impone trabajar de forma conjunta las dos obras.

Nauck (1964 [1889²]) identifica veintitrés fragmentos y los ordena en tres series: los fr. 65-73 Nauck ${ }^{2}$ atribuidos a Alcmeón en Psófide, los fr. 74-77 Nauck ${ }^{2}$ a Alcmeón en Corinto, y, por último, los fr. 78-87 $\mathrm{Nauck}^{2}$, cuya atribución se mantiene incierta ${ }^{7}$. Van Looy (1964: 78-131), en su edición de las tragedias fragmentarias de Eurípides, sigue la numeración de Nauck $^{2}$ y añade fragmentos publicados después de Nauck ${ }^{2}$

sus tíos en medio de la cólera por las burlas infligidas por las víctimas (fr. 77-89 Radt, 1999 [1975]: 140-145, y Lucas de Dios 1983: 50-53); a Alcmeón, en Alcmeón y Epígonos de Sófocles (fr. 108-110 y 185-190 Radt, 1999 [1975]: 149-150 y 183-186, y Lucas de Dios 1983: 59-61 y 91-95), a Medea, en Escitas de Sófocles, en tanto el fratricidio de Apsirto podría ser producto del arrebato de furor pasional al saberse abandonada por Jasón (fr. 546-552 Radt, 1999 [1975]: 415-418, y Lucas de Dios 1983: 277-278); tal vez a Filomela y Procne, en Tereo de Sófocles, quienes matan a Itis, el hijo de Tereo y Procne (fr. 581-595b Radt, 1999 [1975]: 435-445, y Lucas de Dios 1983: 303-309), y, por último, en Frixo A y B de Eurípides, a Ino, que intenta destruir a sus hijastros Frixo y Hele (fr. 818c, 819-838 Kannicht, 2004: 856-876). Sobre los fragmentos conservados de las tragedias sobre el mito de Atamante véase Caballero González (2011: 106-323) y sobre el de Ixión, González Ruz (2013: 47-55).

$5 \quad$ Las traducciones al español de las tragedias fragmentarias son pocas. La editorial Gredos publicó traducciones de los fragmentos de Sófocles (Lucas de Dios 1983) y de Esquilo (Lucas de Dios 2008), sin el texto en griego. Respecto de Eurípides, no hay ninguna traducción completa de sus fragmentos al español y las traducciones de piezas fragmentarias individuales son muy escasas.

6 Para un estudio general sobre las fuentes de los fragmentos de las tragedias perdidas de Eurípides, además de la introducción a la selección de Collard, Cropp \& Lee (1995), puede consultarse Jouan \& van Looy (2002 [1998]: xi-lxxxiii) y Collard (2005).

$7 \quad$ La edición de Tragicorum Graecorum Fragmenta de Nauck que se reimprimió en 1964, acompañada de una actualización de Snell, sigue la segunda edición, la de 1889, por lo que se la cita mediante la abreviatura Nauck². 
(van Looy 1964: 121-131). Luego, Jouan \& van Looy (2002 [1998]) editan con otra numeración y añaden algunos fragmentos publicados después de Nauck $^{2}$. Atribuyen a las dos tragedias dieciséis fragmentos, ocho a cada una. Kannicht (2004), seguido por Collard \& Cropp (2008), respeta la numeración de $\mathrm{Nauck}^{2}$, pero agrega nuevos fragmentos y excluye otros, como los fr. $67 \mathrm{Nauck}^{2}$ (=88a Kannicht) y $68 \mathrm{Nauck}^{2}$ (= 304a Kannicht), adjudicados a Alcmena y Belerofonte respectivamente. Asimismo, Kannicht (2004) atribuye siete fragmentos a Alcmeón en Psófide (fr. 65- 66 y 69-73) y cinco a Alcmeón en Corinto (fr. 73a-77), y considera otros doce fragmentos atribuibles a una u otra obra (fr. 78-87a).

\section{Datos generales sobre Alcmeón en Psófide y Alcmeón en Corinto}

El mito de Alcmeón era uno de los más conocidos en la Antigüedad ${ }^{8}$. De hecho, Aristóteles en Poética (1453a 18-21) señala que la saga constituía uno de los mejores ejemplos de crímenes intrafamiliares y lo ubica primero en la lista junto con Edipo, Orestes, Meleagro, Tiestes y Télefo?.

A partir de las fuentes antes mencionadas sabemos que la reina de Argos, Erífila, había sido sobornada por Polinices, desterrado de Tebas por su hermano Eteocles, con el collar de Harmonía (el regalo de los dioses para su boda con Cadmo, obra de Hefesto) para que solicitara a su esposo, Anfiarao, que participara de la expedición de los Siete contra Tebas ${ }^{10}$. Debido a un juramento previo con Adrasto, el hermano de Erífila, Anfiarao debía someterse al arbitrio de su esposa ante cualquier pleito o discordia, razón por la que el adivino debe partir hacia la expedición. Antes de hacerlo, solicita a su hijo, Alcmeón, todavía pequeño para participar, que se vengue de Erífila porque, siendo adivino, sabía que moriría en Tebas. Recordemos que Anfiarao era descendiente del linaje de adivinos de Melampo ${ }^{11}$.

Tiempo después, el hijo de Polinices, Tersandro, decide regresar a Tebas para vengar la muerte de su padre a manos de su tío, Eteocles, junto con los hijos de los otros héroes caídos, los Epígonos. Un oráculo advierte a Tersandro de que para vencer en la expedición debe convocar a Alcmeón para conducir las tropas. Para que Alcmeón participe, siguiendo el ejemplo de su padre, Tersandro le hace un nuevo regalo a Erífila para que persuada a su hijo a participar, en este caso se trata de un vestido que hace juego con el collar de Harmonía. Como consecuencia, el héroe parte a Tebas y consiguen la victoria ${ }^{12}$. Al volver de la

8 La locura de Alcmeón es objeto de numerosas comedias en el siglo IV a. C.; para una lista de las obras, véase Jouan \& van Looy (2002 [1998]: 88-89).

9 Las fuentes del mito de Alcmeón a las que podemos recurrir para reponer el material mítico son: Píndaro, Pítica 8; Tucídides 2.102; Apolodoro 3.5-7; Ovidio, Metamorfosis 9.403-417; Higino, Fábula 73; Plutarco, Obras morales y de costumbres, De audiendis poetis 13, y Pausanias 7.24.4, 8.24.8 y 10.10.2. Sobre las fuentes literarias y artísticas del mito de Alcmeón, consúltese Gantz (1993: 14-15, 507-508, 522-527 y 565).

10 Higino (s. I a.C.) atribuye la confección del collar a Adrasto en la Fábula 73.

11 Esquilo dedica varios versos a la figura de Anfiarao en su tragedia Siete contra Tebas (vv. 568-596), en los que contrasta su moderación con la desmesura de los otros generales.

12 En las tragedias áticas prevalece la versión, atestiguada en el poema épico Epígonos, según la cual Alcmeón mata a la madre luego de participar en la expedición a Tebas. Sin embargo, sabemos de la existencia de otro poema épico sobre la saga, Alcmeónida, en el que el héroe mata a su madre y se vuelve loco antes de la expedición. Los fragmentos de Epígonos y de Alcmeónida puede consultarse en la edición de Bernabé (1996 [1987]: 29-31 y 32-35). Para un estudio sobre las versiones épicas diferentes atestiguadas en Alcmeónida y Epígonos, véase Legras (1905: 89-109), Severyns (1928: 224-237) y Olivieri (2010: 302-303). Por otra parte, Anfiarao tuvo un 
expedición ${ }^{13}$, Alcmeón asesina a su madre con una espada, con un tajo donde llevaba el funesto collar ${ }^{14}$.

En las tragedias Alcmeón en Psófide y Alcmeón en Corinto, Eurípides explora - tal como Esquilo en los dramas perdidos Epígonos y Sófocles en Alcmeón, Epígonos, y, tal vez, Erifila - las consecuencias que sufre el héroe por haber matado a su madre, que lo llevan a abandonar Argos, su ciudad de origen. Sin embargo, constituyen dos obras de temática muy distinta: Alcmeón en Psófide, producida primero, trata la muerte del héroe, y, en cambio, Alcmeón en Corinto se enfoca en el futuro y la descendencia del matricida, alejándose del relato tradicional.

Eurípides representó Alcmeón en Psófide junto a Cretenses, Télefo y Alcestis en el 438 a.C. y obtuvo el segundo puesto ${ }^{15}$. Las fuentes que relatan la historia completa de Alcmeón en Psófide son Pausanias (Descripción de Grecia 8.24.8) y Apolodoro (Biblioteca 3.7.5-6), cuyo relato sirve para establecer un orden relativo de los fragmentos conservados. Dado que el héroe tiene dos estancias en la ciudad de Psófide, la crítica se debate sobre a cuál de las dos visitas hace referencia la tragedia, cuestión sobre la que volveré más adelante.

Tras la expedición a Tebas comandada por Tersandro y el asesinato de Erífila, el rey de Psófide, Fegeo, acoge a Alcmeón y le ofrece en matrimonio a su hija (Alfesibea, según Pausanias 8.24.8 o Arsínoe en la versión de Apolodoro 3.7.5-6). La joven esposa recibe el collar y el vestido de Harmonía. Ahora bien, la purificación ofrecida por Fegeo no es suficiente y Alcmeón debe abandonar la ciudad, ya que, además de padecer episodios de locura, la tierra se vuelve impura por la mancha del asesinato, dato que encontramos en la versión de Apolodoro, pero no en la de Pausanias. El oráculo de Delfos vaticina que debe habitar una tierra que no hubiese visto la luz del sol al momento del matricidio (Tucídides, La Guerra del Peloponeso 2.102.3-5) ${ }^{16}$. Luego de vagar durante un largo tiempo, como Orestes, el héroe encuentra la tierra formada a partir de los detritos del río Aqueloo. El dios purifica a Alcmeón y le ofrece en matrimonio a su hija, Calírroe. Entonces el héroe se establece y da el nombre de Acarnania a la región por su hijo Acarnano. Ahora bien, la nueva esposa reclama para sí el collar y el vestido de Harmonía, por lo que Alcmeón se dirige por segunda vez a Psófide. El héroe intenta convencer a Fegeo de que le devuelva los regalos diciéndole que debe consagrarlos a Delfos para poder ser purificado. El rey se entera de la intención de Alcmeón porque un criado lo delata y ordena la muerte del héroe a manos de sus hijos. Alfesibea se niega a participar del crimen y es vendida como esclava $^{17}$. Al oponerse a su familia de origen e inclinarse por su esposo que, por otra

lugar destacado en el poema Tebaida, del cual se conservan algunos fragmentos, que contaba la historia de la guerra entre Eteocles y Polinices (Bernabé 1996 [1987]: 20-28), y Estesícoro compuso Erifila, cuyos fragmentos se pueden consultar en Davies \& Finglass (2014: 126-128), obra que probablemente estaba centrada en el papel que cumplió la reina en las dos expediciones a Tebas. Asimismo, se han conservado fragmentos de una epopeya sobre la estirpe de Melampo, Melampodia, atribuida a Hesíodo, que pueden consultarse en Merkelbach \& West (1967: 133-138).

13 Según Píndaro, en la Pítica 8 (vv. 39-50), Anfiarao había profetizado la segunda expedición a Tebas.

14 Sabemos por Aristóteles que hubo un trágico del siglo IV a. C., de nombre Astidamante, que compuso un Alcmeón con una variante respecto a la trama: el héroe mataba a su madre en un estado de ignorancia (Poética 1453b).

15 La información proviene del argumento de Alcestis atribuido a Aristófanes de Bizancio.

16 Véase Detienne (2001: 160-162) para un análisis de la palabra oracular de Delfos en el mito de Alcmeón. El autor destaca que el dios Apolo traza un camino de vagabundeo desmesuradamente largo para los asesinos cuyos crímenes inspiró.

17 Propercio (1.15.15-16) la menciona junto a otras amantes desdichadas, a saber: Calipso, Hipsípila y Evadne. 
parte, ya tenía una nueva mujer, el personaje de Alfesibea representa un modelo de figura femenina diferente respecto de las figuras de Erífila y Calírroe ${ }^{18}$.

Para Collard \& Cropp (2008: 80-81) la tragedia Alcmeón en Psófide terminaba con la narración de un mensajero de la muerte de Alcmeón y la orden de Apolo de que el collar debía ser consagrado al héroe. Si bien no forma parte de los objetivos de este trabajo hacer especulaciones sobre lo que sucedía en la obra, considero que la propuesta de Collard \& Cropp resulta sumamente valiosa por el sentido político atribuido al final de la obra. A la muerte de Alcméon sigue la consagración del collar, que supone la institución de un ritual, de manera que se sigue el patrón trágico, señalado por Seaford (1995: 344-344), que consiste en la destrucción de la familia real seguida de la instauración de un ritual en beneficio de la polis, que conduce a la cohesión comunal.

Por otra parte, es importante señalar que, a diferencia de Orestes (como retrata Esquilo en Euménides 754-766), Alcmeón no encuentra la paz para sus tormentos, sino que es asesinado y su tumba en Psófide se convierte en un lugar sagrado. Los hijos que había tenido con Calírroe vengan a su padre matando a Fegeo y a su descendencia, y, además, se ocupan de consagrar el mortífero collar a Apolo en Delfos.

Los fragmentos conservados de Alcmeón en Psófide suman unos quince versos y lamentablemente arrojan pocos datos sobre el argumento de la tragedia. La crítica, como he señalado, se debate acerca de si la tragedia de Eurípides trata sobre la primera o la segunda llegada del héroe a Psófide y, también, sobre la posibilidad de que se representara una escena de locura ${ }^{19}$. La mayor parte de los estudiosos, influenciados por Schadewaldt (1952: 51 y 53), que para su argumentación se basa en la atribución del fr. 86 a Alcmeón en Psófide, sostienen que se trata de la segunda visita del héroe a Psófide, en la que se propone recobrar el collar para dárselo a su nueva esposa Calírroe ${ }^{20}$. Sin embargo, Jouan \& van Looy (2002 [1998]: 111) entienden que forma parte de Alcmeón en Corinto, y Kannicht (2004: 216-217) ubica el fr. 86 entre aquellos fragmentos atribuibles a una u otra obra.

Por mi parte, para resolver si Alcmeón en Psófide trata la primera o la segunda estancia me centraré en los dos fragmentos que se refieren al collar de Harmonía, el 70 Kannicht y el 79 Kannicht. El fr. 70 Kannicht ha sido transmitido de forma indirecta en un escolio a la Nemea 4, v. 32, de Píndaro y su atribución a Alcmeón en Psófide es conjetural. En el fragmento se relaciona a Alcmeón con otro matricida, Edipo: òs

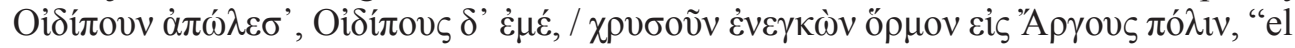

18 García Gual (2014: 85-89) analiza en la saga de Alcméon los conflictos entre las dos instituciones familiares básicas de la sociedad griega, el génos, la 'estirpe', y el gámos, el 'matrimonio'.

19 La locura del personaje parece encajar mejor en Alcmeón en Psófide, si bien se ha intentado con dificultad ubicar también su presentación en Alcmeón en Corinto (Zielinski 1922: 309, seguido por Webster 1967: 40 y 266), cuestión sobre la que volveré al analizar los fragmentos de la obra de Ennio sobre el mito de Alcmeón. Basándose en la reconstrucción que hace Schadewaldt de las dos obras que Accio dedica a la saga de Alcmeón (Alcmeón y Alfesibea), que tomarían como modelo Alcmeón en Psófide de Eurípides, Webster (1967: 40) sostiene que es muy posible que se representara una escena de locura en la tragedia ática. Si bien en el fr. 86 Kannicht, conservado en un papiro que puede consultarse en Vitelli (1949: $\left.\mathrm{n}^{\circ} 1302,54-56\right)$, se registran términos vinculados a la esfera de la manía, como una forma del verbo $\mu \alpha i ́ v o \mu \alpha \mathrm{r}(\mu \alpha \mathrm{lvo} \mu[)$ y el sustantivo $\mu \omega \rho i ́ \alpha$ ( $\mu \omega \rho i ́ \alpha v)$, el estado de deterioro es tan alto que, desde mi punto de vista, no tiene sentido emplearlos para defender una hipótesis como la de representación en escena de una escena de locura, que requiere un alto nivel de elaboración.

20 Véase Medda (2011 [2001]: 66), que detalla los autores que entienden que en la tragedia de Eurípides se representaba la primera estancia del héroe en Psófide y aquellos que piensan que se trataba de la segunda. 
que destruyó a Edipo, y como (el hijo de) Edipo a mí21, tras llevar el collar de oro a la ciudad de Argos" ${ }^{22}$. Probablemente quien enuncia los versos sea Alcméon y se esté refiriendo a Apolo, cuyo oráculo ocasionó la ruina de Edipo (Musso \& Burlando 2009: 159, y García Gual 2014: 68). Es importante reparar en que se asocia la joya con la acción de destruir la vida de un personaje.

Por otra parte, en el fr. 79 Kannicht, transmitido en la Antología $(4,19,25)$ de

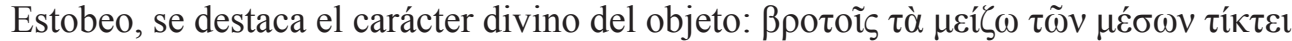

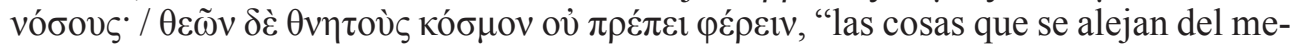
dio entre los mortales engendran enfermedades. No es conveniente que los mortales lleven el ornamento de los dioses". Los fr. 70 y 79 Kannicht presentan el mismo problema, no se especifica a cuál de las dos tragedias que escribió Eurípides pertenecen. Jouan \& van Looy (2002 [1998]: 104) afirman que el fr. 70 Kannicht pertenece a Alcmeón en Psófide, y Kannicht (2004: 209) y Collard \& Cropp (2008: 95) lo ubican de forma conjetural en la misma tragedia. En tanto, respecto del fr. 79 Kannicht, Webster (1967: 42-43), Jouan \& van Looy (2002 [1998]: 105) y Collard \& Cropp (2008: 95) estiman que pertenece a Alcmeón en Psófide; Kannicht (2004: 215), por su parte, lo ubicó entre aquellos fragmentos que pueden pertenecer a una u otra tragedia.

Debido al papel que cumple el collar en la relación entre Alcmeón y la ciudad de Psófide, me adhiero a la hipótesis de que los dos fragmentos antes citados pertenecen a Alcmeón en Psófide y no a Alcmeón en Corinto, dado que no tendría sentido que los fragmentos sobre la joya formaran parte de una tragedia que se enfoca en el futuro y la descendencia de Alcmeón, con un final feliz alejado del relato tradicional. El énfasis del carácter funesto de la joya en los dos fragmentos y el hecho de que Alcmeón muere en la segunda estancia en Psófide me inclinan a pensar que en la tragedia se escenificaba el segundo viaje.

Sobre el collar, García Gual (2014: 17) acota que se trata de un objeto precioso que ejerce una extraordinaria seducción y provoca fatalidades cuando se lo emplea mal: un presente de bodas que termina siendo usado para la desunión familiar, ya que Erífila y Calírroe envían a sus esposos a la muerte por poseer la joya. En definitiva, la afición a los regalos de una mujer, primero su madre y luego su esposa, determina el destino de Alcmeón.

En este sentido, resulta de interés el fr. 78 Kannicht, citado a continuación, por expresar una apreciación negativa de la mujer, cuestión que retomaré en el apartado siguiente. La atribución del fragmento se mantiene imprecisa, pero podría ubicarse

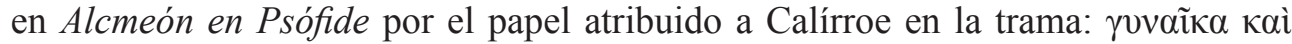

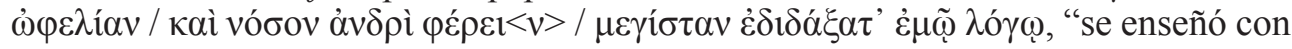
mi discurso que la mujer lleva al hombre tanto el mayor socorro como también la mayor enfermedad". Si bien, cabe señalar que la mujer mencionada en el fragmento

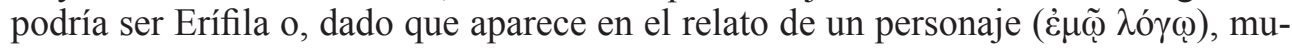
chas otras. Respecto de Calírroe, sabemos, por Ovidio (Metamorfosis 9.403-417), que la joven, si bien envió a su esposo a la muerte al pedirle que regresara a Psófide, no había previsto la emboscada y, además, una vez muerto Alcmeón, pide a Zeus que

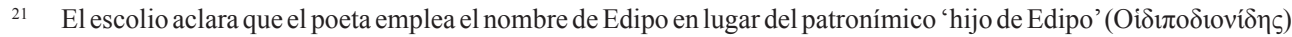
para referirse a Polinices; $c f$. Jouan \& van Looy (2002 [1998]: 104).

22 El texto griego de los fragmentos citados de las tragedias Alcmeón en Psófide y Alcmeón en Corinto en el presente trabajo corresponde a la edición de Kannicht (2004) y su traducción me pertenece en todos los casos, como también la de los otros textos griegos y latinos citados. 
sus hijos, aún niños, se hagan hombres para vengarlo ${ }^{23}$. La interpretación propuesta del fr. 78 Kannicht sigue la hipótesis antes indicada de que la tragedia trata la segunda estancia de Alcmeón en Psófide.

Alcmeón en Corinto (407-406 a.C.) fue compuesta, junto con Ifigenia en Áulide y Bacantes $^{24}$, cuando Eurípides ya había dejado Atenas y se encontraba en la corte de Arquelao I de Macedonia. Su hijo — o según otra fuente, el sobrino - llevó a escena la trilogía y obtuvo el primer puesto (Jouan \& van Looy 2002 [1998]: 92). En la obra dedicada a Alcmeón se escenifica el reencuentro del héroe con los hijos que había tenido con Manto, la hija de Tiresias, cedida como botín de la expedición a Tebas. Por las crisis provocadas por la enfermedad, el héroe había decidido poner a los dos niños, de nombre Anfíloco y Tisífone, bajo la tutela de Creonte, rey de Corinto.

El fr. 73a Kannicht, transmitido por un gramático anónimo en un papiro (POxy

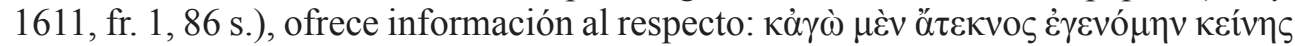

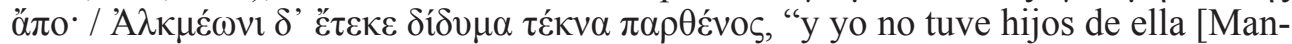
to], pero la joven parió dos hijos para Alcmeón”. Collard \& Cropp (2008: 87-88) entienden que el fr. 73a Kannicht probablemente forme parte del prólogo a cargo de Apolo. El empleo de $\pi \alpha \rho \theta \varepsilon ́ v o s$ para designar a Manto resulta llamativo, ya que, según las otras fuentes sobre el mito, la joven había sido entregada como esposa a Alcmeón ${ }^{25}$. Para Jouan \& van Looy (2002 [1998]: 106) puede interpretarse como un indicio de una violación por parte de Alcmeón a Manto. En la versión de Eurípides, Apolo no tiene hijos con Manto; sin embargo, según otras fuentes, como, por ejemplo, Apolodoro (Epítome 6.3), Manto le dio un hijo de nombre Mopso.

La trama mítica continúa del siguiente modo: la esposa de Creonte, celosa de la extraordinaria belleza de Tisífone, la vende como esclava, y el héroe la compra sin saber que se trata de su propia hija. La crítica ha reconstruido la trama de Alcmeón en Corinto tomando los datos ofrecidos por Apolodoro (Biblioteca 3.6.7). Dado que el único testimonio de los acontecimientos representados en Alcmeón en Corinto es Apolodoro, se conjetura que constituyen una innovación de Eurípides ${ }^{26}$. Se trata de sucesos temporalmente anteriores a los representados en Alcmeón en Psófide, pero posteriores a la victoria de los Epígonos en Tebas, porque a causa de su enfermedad debe abandonar a sus hijos ${ }^{27}$. En comparación con Alcmeón en Psófide, en Alcmeón en Corinto se muestra una faceta diferente del héroe, en tanto se lo representa con

23 Al contar la historia de Iolao en Metamorfosis (9.403-417), Ovidio resumen la saga de los Siete contra Tebas y el mito de Alcméon en un oráculo de Temis, del que no hay registro en la tradición mítica. El tema central en la versión de Metamorfosis es la cuestión de la pietas. Por un lado, el dios Apolo concede no morir a Anfiarao y que la tierra se abra para que baje en su carro a los Infiernos debido a que era un sacerdote consagrado a su culto, es decir, por su pietas. Por otro lado, el poeta latino no desarrolla los pormenores de la saga de Alcmeón sino que se centra en la cuestión de la impietas: facto pius et sceleratus eodem, "piadoso y contaminado por la misma acción" (Metamorfosis 9.408). El pasaje citado de Metamorfosis de Ovidio corresponde a la edición de Tarrant (2004). Cabe señalar que en el poema se establece una clara oposición entre padre e hijo respecto de la pietas, que puede relacionarse con que en el género trágico Anfiarao es un personaje mesurado (Esquilo, Siete contra Tebas 568-596) y Alcmeón asesina a su madre en un estado de locura.

24 La información proviene de los escolios a los vv. 66-67 de Ranas de Aristófanes.

25 El término $\pi \alpha \rho \theta \varepsilon ́ v o \varsigma$ indica el estado de la joven mujer que aún no se ha casado (Calame 1977: 65 y Loraux 1993 [1984]:162), por lo que prefiero traducir el sustantivo por 'joven mujer', en lugar de 'virgen' o 'doncella', como suele traducirse al español.

26 Sobre las innovaciones de Eurípides en la saga del matricida en Alcmeón en Corinto, véase Jouan (1990: 164166). Por su parte, Olivieri (2013: 161) no cree que los eventos sean totalmente inventados por el poeta.

27 Véase Olivieri (2010) que reconstruye la geografía mítica del recorrido de Alcmeón a partir de fuentes épicas y trágicas. 
vida y curado de su enfermedad, si bien los acontecimientos no dejan de estar vinculados con sus episodios de manía.

La acción de la tragedia empezaría con el regreso del héroe a Corinto, acompañado por Tisífone, sin saber que era su hija, y sin reconocer a Anfíloco cuando lo ve. En el final se produciría una típica escena trágica de reconocimiento y reencuentro (Collard \& Cropp 2008: 87). ${ }^{28}$ De Poli (2018: 158) hipotetiza que la anagnórisis sería entre Alcmeón y Anfíloco, a quien Creonte había encargado matar a su padre. La reina desvelaría el vínculo y permanece incierto si Tisífone estaba presente como personaje mudo en el escenario o si había otra escena más de reconocimiento, que seguramente debía acontecer antes respecto del reconocimiento entre padre e hijo, que es el evento relevante para la resolución de la trama ${ }^{29}$. Recordemos que Eurípides utiliza, en algunas ocasiones, como en Ifigenia entre los tauros e Ión, las escenas de reconocimiento para evitar un peligro mortal en el final. Las escenas se introducen cuando uno de los personajes puede llegar a morir a causa de la falta de conocimiento del vínculo (De Poli 2018: 160-161). Por otra parte, además, se supone que en el final Apolo anunciaría que Anfíloco fundaría Argos Anfiloquía (Collard \& Cropp 2008: 87$)^{30}$.

\section{Alcmeón y Orestes}

Dada la serie de características que comparten los personajes míticos de Alcmeón y Orestes, se impone mirar a la figura trágica del hijo de Agamenón para interpretar los fragmentos conservados de las tragedias de Eurípides que abordan el mito de Alcmeón ${ }^{31}$. Establecer paralelos entre una tragedia de la que tenemos fragmentos y otra conservada de forma completa, que tratan sobre mitos que comparten puntos en común, ofrece buenos resultados. Así lo demuestra Carpanelli (2018), por ejemplo, que analiza una tragedia completa y otra fragmentaria sobre dos personajes castigados por Dioniso con la locura por prohibir su culto. Se trata de los fragmentos de la tetralogía sobre Licurgo compuesta por Esquilo y Bacantes de Eurípides, drama que, cabe recordar, tiene dos lagunas importantes.

Alcmeón y Orestes son originarios de Argos, matan deliberadamente a su madre para vengar a su padre muerto, son castigados con la locura, andan errantes y se recuperan gracias a la participación de $\mathrm{Apolo}^{32}$. No he incluido la persecución de

28 Francisetti Brolin (2013: 79) destaca que Eurípides presenta una versión de la saga de Alcméon que contrasta con la tradición corintia. En Alcmeón en Corinto, compuesta mientras se encontraba en la corte de Arquelao, el poeta se muestra fiel a su tierra natal, Atenas, y en contra de Corinto, ciudad considerada por los atenienses la responsable del desastre en Sicilia durante la Guerra del Peloponeso.

29 Véase Karamanou (2012), que analiza el valor sociopolítico de las obras de Eurípides en relación con el tema del reencuentro de parientes, e incluye las tragedias fragmentarias. El hecho de que en el fr. 76 Kannicht (ópã $\tau \varepsilon$

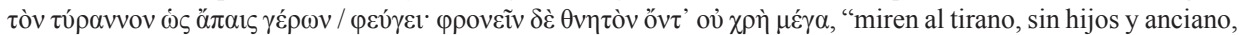
cómo huye. Siendo mortal no se debe pensar de modo arrogante"), referido a Creonte, se hable de que se lo castiga con el exilio sugiere que el personaje cumplía un papel negativo. Además, sabemos por Apolodoro que la tragedia finalizaba con un mito fundacional que establecía una relación entre la tradición mítica y el territorio.

30 Según Tucídides (La Guerra del Peloponeso 2.68.3), el fundador había sido el hermano de Alcmeón, de igual nombre que su sobrino, Anfíloco.

31 Ya desde la Antigüedad se asociaron los mitos; véase Platón (Alcibíades II 143c) y Aristóteles (Poética 1453a 18-21).

32 Recordemos que en Electra de Sófocles (vv. 838-848), el Coro anima a Electra evocando la venganza de Alcmeón, de manera que el mito sirve de pauta para los hijos de Agamenón. 
las Erinias porque la fuente antigua del dato es Alcmeón de Ennio y sabemos que el autor latino reelaboraba los modelos con libertad, cuestión a la que me referiré más adelante $^{33}$. Ahora bien, los mitos de Alcmeón y Orestes presentan una diferencia sustancial respecto de la ejecución del matricidio: la muerte de Erífila constituye una venganza personal sin consecuencias dinásticas, en cambio, la de Clitemnestra sí las tiene. Por otra parte, Anfiarao ordena a su hijo el cumplimiento del asesinato y luego Apolo aconseja realizarlo (Diodoro, Biblioteca histórica 4.66), y, en el caso de Orestes, es el dios el que exige el matricidio (Jouan \& van Looy 2002 [1998]: $88)^{34}$. Además, Clitemnestra es una figura representada en el género trágico como de carácter fuerte, capaz de asumir la planificación de un crimen e incluso exponer los motivos ${ }^{35}$; en cambio, Erífila no ejecuta el crimen de su marido, por lo que su conducta no genera en el auditorio el mismo efecto que la de Clitemnestra. Si bien la afición a recibir regalos la impulsa a la traición, la ubica en la lista de mujeres funestas de la mitología griega ${ }^{36}$.

Homero cuenta que Erífila se encuentra entre las sombras que avista Odiseo en su visita al Hades, en el famoso "Catálogo de las heroínas" (Odisea 11.326-327) 37 . Al detallar el linaje de Melampo en el encuentro entre Telémaco y Teoclímeno, se cuenta brevemente la muerte de Anfiarao en el asedio a Tebas y se indica que la causa fueron los regalos dados a su mujer, sin mencionar la posterior venganza de su hijo (Odisea 15.243-248). Ahora bien, no se hace referencia al matricidio en la Nékvia, del mismo modo que es silenciado el asesinato de Clitemnestra cuando se habla de la historia de Orestes (Odisea 1.29-41, 3.193-198, 232-235, 247-275, 303-312 y 4.512-547).

Me ocuparé, en primer lugar, del matricidio, acción que, ya se ha comentado, Orestes y Alcmeón llevan adelante, pero con diversas consecuencias. El asesinato de un phílos constituye un elemento común a la mayor parte de los episodios de locura presentes en el teatro griego del siglo $\mathrm{V}$ a. C. ${ }^{38}$. Con cierta regularidad, encontramos que se ubica un crimen de sangre en la trama mítica como causa o consecuencia de la manía. El matricidio es un crimen menos frecuente en la tragedia que el filicidio. Al respecto, el trabajo de Delcourt (1959) resulta paradigmático y analiza de forma completa las figuras de Orestes y Alcmeón en la mitología griega. La autora destaca lo absurdo del pedido de venganza de Anfiarao a su hijo, puesto que si él mismo ejecutara el crimen de Erífila constituiría un acto menos grave (Delcourt 1959: 41) ${ }^{39}$.

33 Apolodoro menciona la persecución en su presentación del mito (Biblioteca 3.7.5).

34 Consúltese Esquilo, Coéforas 899-902, y Apolodoro, Biblioteca 3.6.2 y 3.7.5. Sobre la desesperación que genera el pedido de Anfiarao en Alcmeón, véase el fr. 201 Radt de Erifila de Sófocles.

35 Véase, por ejemplo, Esquilo, Agamenón 11, 351 y 1380-1398, inter alios multos.

36 Debe recordarse que la locura de Ixión, descrita en Las mujeres de Perrebia de Esquilo, tragedia de la que se conservan fragmentos, tiene puntos en común con la de Orestes tal y como se describe en Coéforas 288. La rabia que empuja a Orestes a vengar la muerte de su padre tiene su paralelo en la enajenación que poseyó a Ixión y lo llevó a matar a su suegro, Eyoneo, por lo que podría pensarse en llevar adelante un estudio comparativo con los fragmentos de Alcmeón. Decidí no hacerlo porque los fragmentos de Las mujeres de Perrebia no aportan datos sobre el estado de enajenación y, en lo que respecta al asesinato, apuntan a la práctica de probar y luego escupir la sangre del enemigo muerto, conducta que no tiene paralelo en las tragedias de Eurípides sobre Alcmeón.

37 Según Pausanias 10.29.7, el pintor Polignoto la representó en el Hades llevando en el cuello, debajo del vestido, el fatídico collar de bolas de oro.

38 Véase Belfiore (2000: 164-165), que estudia la acción de Alcmeón como uno de los casos de perversión de los lazos de philía.

39 Desde el psicoanálisis, Bunker (1944: 202) advierte que el asesinato de Erífila y el matrimonio de Edipo con Yocasta son seguidos por consecuencias que podrían considerarse idénticas, en tanto llevaron esterilidad sobre 
Por otra parte, Damet (2012: 115) señala el hecho de que los matricidios en el género trágico son cometidos de forma voluntaria, es decir, el matricida es consciente de que se trata de su madre, a diferencia de los parricidios, que son cometidos en ignorancia, ya sea que se desconoce el vínculo o los asesinos son manipulados por una tercera persona.

En el fr. 69 Kannicht, adjudicado de forma conjetural a Alcmeón en Psófide, se

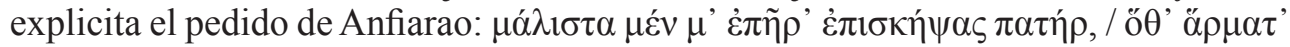

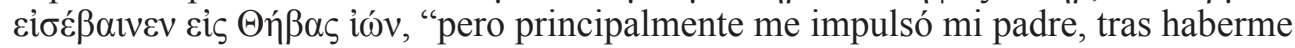
conjurado (a hacerlo), cuando subía a su carro para ir a Tebas" ${ }^{\prime 40}$. El contexto del fragmento citado es un comentario de un escoliasta anónimo a un pasaje del libro III de Ética Nicomaquea (1110a) de Aristóteles sobre la definición de las acciones voluntarias e involuntarias. Para tipificar las acciones mixtas, aquellas realizadas por fuerza o necesidad, el filósofo cita el caso de Alcméon y reivindica la libre decisión respecto del asesinato de su madre ${ }^{41}$. Además, señala que en su caso era preferible morir, porque estima débiles las causas que lo llevaron a cometer el crimen.

El origen del asesinato es, según el fr. 69 Kannicht, la maldición de Anfiarao,

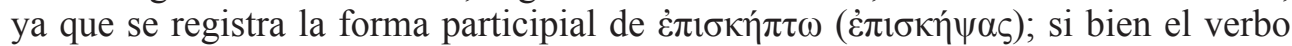
significa 'mandar a alguien hacer algo', también puede traducirse como 'conjurar a

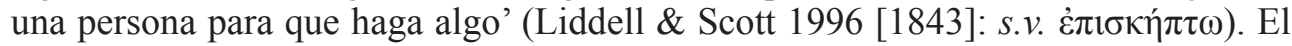
contexto del fragmento citado dirige la interpretación en este último sentido, ya que el escoliasta agrega que Anfiarao amenazó a su hijo con una plaga que golpearía al

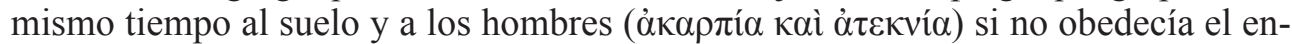
cargo (Jouan \& van Looy 2002 [1998]: 103).

En segundo lugar, me referiré al aspecto físico de los personajes de Alcmeón y Orestes. Focio de Constantinopla (Lexicon $\alpha$ 448) transmite el fr. 78a Kannicht, que apareció posteriormente a la edición de $\mathrm{Nauck}^{2}$, sin indicaciones de a cuál de las dos tragedias pertenece:

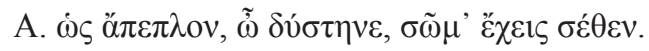

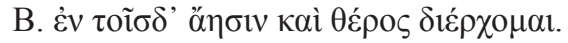

— ¡Cuán sin peplos, desgraciado, tienes tu cuerpo!

- Con ellos atravieso el viento y el calor.

Schadewaldt (1952: 58) entiende que el fr. 78a Kannicht forma parte del primer episodio de Alcmeón en Psófide donde se encontraban Fegeo y Alcmeón; en tanto Webster (1967: 40) sostiene que por la métrica pertenece a Alcmeón en Corinto. No es posible determinar quién podría ser el primer interlocutor, el segundo podría ser Alcmeón (Collard \& Cropp 2008: 95). Por mi parte, sigo a Schadewaldt (1952: 58)

la tierra, sucesos interpretados como una castración. Si bien para el análisis aquí propuesto la interpretación psicoanalítica de la castración no es relevante, estimo que debe ser tomado en cuenta el hecho de ubicar un nuevo punto de contacto entre el mito de Edipo y el de Alcmeón. Lo cierto es que el fr. 70 Kannicht, antes analizado, vincula de forma explícita los mitos: el hijo de Edipo, Polinices, y, a su vez, su hijo, Tersandro, son actores fundamentales en el mito de Alcmeón.

40 En la crátera de origen corintia conservada en la Antikensammlung de Berlín se representa la partida del rey de Argos (La despedida de Anfiarao. Crátera, figuras negras, 600-550 a.C. Antikensammlung, Berlín, F1655, Beazley Archive ${ }^{\circ}$ 9036825). Es posible identificar rápidamente la figura de Erífila porque tiene en sus manos un collar que cuelga hasta el suelo.

41 Guariglia (1997: 141-142) analiza el tratado de Aristóteles y repara en la referencia mitológica. 
en ubicar el fragmento citado en Alcmeón en Psófide y no en Alcmeón en Corinto, porque en la segunda tragedia, si tomamos como una fuente certera la Biblioteca de Apolodoro, no se representaba al personaje cuando padece ataques de locura o inmediatamente después, por lo que no tendría sentido mostrarlo en un estado deplorable, como se lo describe en el fr. 78a Kannicht.

Asimismo, en Orestes se describe el aspecto del hijo de Agamenón ocasionado por la enfermedad, unos días después de haber cometido el matricidio ${ }^{42}$. Electra y

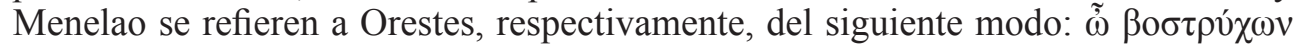

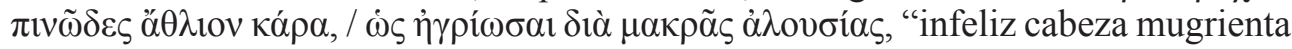
de rulos, qué aspecto salvaje tienes a causa de estar desde hace tanto tiempo sin ba-

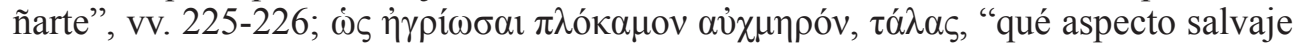
tienes debido a tu cabellera seca, desgraciado", v. $387^{43}$.

El cotejo del fragmento conservado de Alcmeón con los pasajes citados de Orestes permite suponer que, siendo locos, ya sea que hubieran padecido ataques de locura en escena o por haberlos tenido previamente, los personajes compartían el vestuario; por ello podría suponerse que la máscara de Alcmeón tuviese elementos similares a la de Orestes, caracterizada por el pelo despeinado y los ojos llorosos (Medda 2011 [2001]: 42) [4. $^{4}$

Por otra parte, dado que sobre el accionar de Alcmeón en estado de locura no contamos con ningún fragmento, el sector de la crítica que se inclina por la idea de que el personaje padecía ataques en escena retoma testimonios indirectos para abordar el tema. Por ejemplo, Webster (1967: 40), para quien un texto de Taciano, citado a continuación, prueba que había una escena de locura en la obra de Eurípides y además confirma que el personaje de Alcméon llevaba harapos, como señala el fr. 78a Kannicht. Taciano, escritor cristiano del siglo II y fundador del encratismo, habla del actor que representaba el papel de Alcméon en la obra de Eurípides (Discurso a los griegos 24, citado en Kannicht 2004: 207):

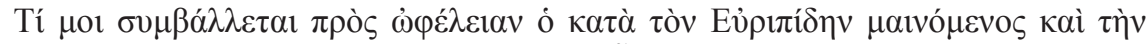

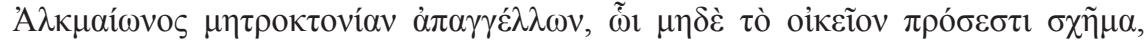

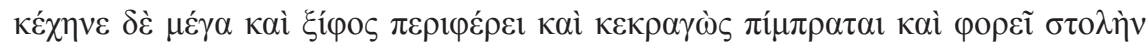

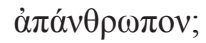

¿Qué ventaja me ofrece el que está loco según Eurípides, y mientras anuncia el matricidio de Alcmeón, que no tiene su aspecto habitual, abre la boca bien grande y mueve su espada y mientras grita se inflama y usa una vestimenta repelente?

En primer lugar, cabe mencionar la dificultad del texto, especialmente respecto

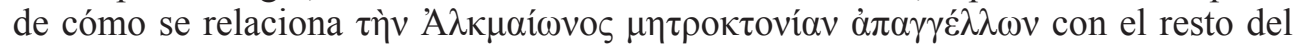
pasaje, ya que parece indicar que hay un personaje, que no es Alcmeón, que está loco y habla del matricidio, hecho que parece poco probable. Kannicht (2004: 207), siguiendo a Nauck ${ }^{2}$, sostiene que Taciano se refiere al actor que interpreta el persona-

42 Sobre el aspecto salvaje del héroe en Orestes de Eurípides, véase Perczyk (2018b: 47-48), que vincula la caracterización del sufrimiento ocasionado por la enfermedad de la locura con el cuadro descrito del personaje de Filoctetes por Sófocles en Filoctetes, tragedia estrenada en el 409 a.C.

43 Los pasajes citados de Orestes de Eurípides corresponden a la edición de Diggle (1994).

44 En el fragmento de Ennio transmitido por Cicerón en Sobre el orador (3, 58, 218), que cito más adelante, se registra el sustantivo inopia, 'escasez', para describir el aspecto del personaje de Alcmeón. 
je. Desde este punto de vista, con el que acuerdo, $\dot{\alpha} \pi \alpha \gamma \hat{\varepsilon} \lambda \lambda \omega v$ se refiere al hecho de que el personaje de Alcmeón relata el matricidio mientras da síntomas de enloqueci-

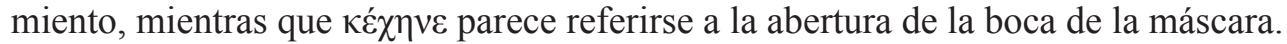

La descripción de la conducta y el atuendo del personaje del pasaje citado de Taciano, que grita, blande una espada y lleva puesta ropa salvaje, recuerda el comportamiento del protagonista de Orestes de Eurípides:

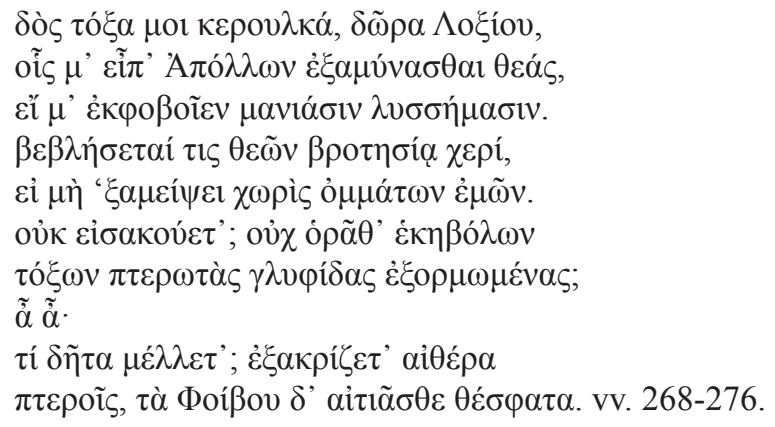

Dame el arco de puntas de cuerno, regalo de Loxias, con el que Apolo me dijo que alejara a las diosas, si me aterrorizaban con enloquecidos delirios. Alguna de las diosas será alcanzada por mi mano mortal, si no se aparta de mis ojos. ¿No escuchan? ¿No ven las flechas aladas lanzándose del arco que hiere de lejos? ¡Ay, ay! ¿Qué esperan entonces? ¡Suban al aire con las alas! ¡Acusen a los oráculos de Febo!

Por otra parte, sabemos que hubo varias tragedias latinas que trataron la leyenda de Alcmeón, incluidas en un apéndice en la edición de Jouan \& van Looy (2002 [1998]: 113-ss. ${ }^{45}$. Cicerón cita tres fragmentos de la fabula cothurnata Alcmeón de Ennio, de los cuales dos resultan significativos para el presente trabajo. En Cuestiones académicas $(2,89,26-27)$, se hace referencia a que las Erinias perseguían con antorchas al personaje de Alcmeón en la versión de Ennio: caeruleae incinctae igni incedunt, circumstant cum ardentibus taedis, "avanzan cerúleas ceñidas con fuego, me envuelven con antorchas ardientes" (Jouan \& van Looy 2002 [1998]: 114) ${ }^{46}$. Webster (1967: 40) se basa en la introducción que hace Cicerón al fragmento de Ennio, en la que se señala que Alcmeón rogaba por la ayuda de una doncella, para afirmar que en Alcmeón en Corinto se representaba una escena de locura, ya que las únicas doncellas en Alcmeón en Psofis son los miembros del coro y en Alcmeón en Corinto se muestra al protagonista acompañado por Tisífone, que era una doncella. La hipótesis, desde mi punto de vista, resulta demasiado arriesgada en tanto se emplea el contexto de aparición de un fragmento de un autor latino, sobre el que no hay certezas de que haya tomado de modelo la obra de un autor griego, para afirmar que se representaba una escena de locura en la obra griega.

45 Los poetas latinos tomaban las tragedias áticas como modelo para la composición de sus obras. Filippi (2018) estudia la locura en la tragedia latina fragmentaria y aplica la clasificación presentada por Platón en Fedro (265a-b). En el teatro trágico latino, así como se ha visto en el griego, un elemento común a la mayor parte de los episodios de locura es la relación con un crimen familiar (Filippi 2018: 292).

46 Filippi (2018: 295) señala que, en Disputaciones tusculanas (4, 18-19), Cicerón presenta una lista de las pasiones señaladas en los fragmentos de Ennio citados en Cuestiones académicas (2, 89, 22-27). 
Una situación similar acontece con otro fragmento citado por Cicerón, en Sobre el orador $(3,58,218)$, del Alcmeón de Ennio, en el que el héroe describe su situación en el exilio (Jouan \& van Looy 2002 [1998]: 113):

multis sum modis circumventus, morbo, exsilio atque inopia;

Tum pavor sapientiam omnem mi examinato expectorat;

mater ( $\dagger$ alter $\dagger$, cod) terribilem minatur uitae cruciatum et necem, quae nemo est tam firmo ingenio et tanta confidentia quin refugiat timido sanguen atque exalbescat metu.

De muchas maneras soy acosado por la enfermedad, el exilio y la escasez. Además, el pavor me saca a mí, exhausto, toda sabiduría. Mi madre amenaza mi vida con una terrible tortura y una muerte violenta, y nadie tiene un temple tan firme y una seguridad tal que no sienta la sangre fluir por el temor y no palidezca por el miedo.

La figura débil, con un aspecto deplorable, presa del terror y atormentada por la enfermedad, sin duda recuerda más de un verso de la tragedia Orestes (Medda 2011 [2001]: 72-73). Ahora bien, esto no permite afirmar que Ennio se haya basado en la versión de Eurípides sobre la saga de Alcmeón, en tanto sabemos que el autor latino reelaboraba los modelos con mucha libertad, dato extraído de los pocos casos en los que conservamos el original griego.

En definitiva, los pasajes citados en este apartado habilitan hablar de una intertextualidad entre las tragedias de Eurípides sobre los mitos de Alcmeón y Orestes. El motivo del aspecto deplorable o lastimoso como producto de la locura une a los personajes. Ahora bien, que los matricidas compartan características no permite concluir que en la versión de Eurípides del mito de Alcmeón el personaje padeciera ataques de locura en escena porque de ese modo procedió con la leyenda de Orestes. Se ha visto que aquellos fragmentos trágicos en los que se representa a Alcmeón enloquecido, tomados por la crítica para sostener la hipótesis, son testimonios indirectos y no fragmentos de las tragedias de Eurípides.

\section{El míasma}

Para finalizar, me referiré a la cuestión del míasma, un elemento central en la concepción del crimen para la ciudadanía ateniense, el primer auditorio de las tragedias, sobre la que los fragmentos conservados de las tragedias de Eurípides acerca de Alcmeón reflejan su importancia y tienen puntos en común con su representación en otra obra del mismo autor sobre la locura, Heracles. El míasma era la consecuencia automática del asesinato que no dependía de la intención del agente, quien se convertía entonces en un peligro para la comunidad por la contaminación que provocaba, un aspecto que, para el espectador actual, resulta ajeno. Debido a que el asesino contaminaba los espacios de la ciudad, debía ser excluido de todos los asuntos, ya fueran religiosos, sociales o comerciales. Parker (1996 [1983]: 114 y 122) explica que el exilio se constituyó como una forma de purificación, pues 
permitía restablecer el equilibrio perturbado por la polución ${ }^{47}$. El crimen de sangre se constituye como un tema sumamente adecuado para el género trágico y la reflexión de las instituciones que conllevan sus representaciones al constituir un problema legal, en tanto para los griegos el homicidio era una ofensa a la familia de la persona asesinada y los parientes eran los encargados de comenzar las acciones legales en contra del asesino.

Se han conservado tres fragmentos sobre la contaminación y la búsqueda de purificación por parte del héroe argivo. En primer lugar, Miguel Itálico (Epístola 35, Anecdota Oxoniensia III.194.1 Cramer) transmite el fr. 71 Kannicht, adjudicado a

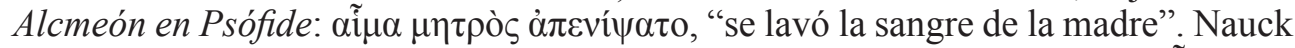

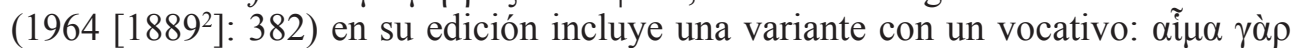
бóv, $\mu \tilde{\eta} \tau \varepsilon \rho, \dot{\alpha} \pi \varepsilon v i ́ \psi \alpha \tau o$, "lavó tu sangre, madre". Siguiendo a Nauck², Webster (1967: 41-42) sostiene que el fragmento corresponde al prólogo, donde el protagonista de la tragedia se lamentaría por haber matado a su madre. Filócomo (en prensa) destaca el valor del vocativo porque habilita la hipótesis de un ataque alucinatorio en escena por parte de Alcmeón. La propuesta de Filócomo se revaloriza si se contempla la posibilidad de un contexto fúnebre, como un sacrificio para aplacar al espectro de Erífila; recuérdese, por ejemplo, la invocación de Electra al difunto Agamenón (Esquilo, Coéforas 130 y ss.). En tanto, García Gual (2014: 68) atribuye el verso a Alcmeón y entiende que quien ejecutó la acción del lavado es Fegeo. Por mi parte, sigo a Kannicht (2004: 209) que elimina la conjetura de Nauck ${ }^{2}$. El fragmento no sigue la métrica que corresponde a un pasaje trágico, por lo que parece más bien tratarse de una paráfrasis (Collard \& Cropp 2008: 85).

La sangre era el elemento contaminante por excelencia, ya que la mancha aparecía al comunicarse dos realidades que debían mantenerse separadas, el mundo de los vivos y el de los muertos (Vernant 1987 [1974]: 112). En ese sentido el fr. 71 Kannicht, aun tratándose de una paráfrasis, resulta fundamental porque permite suponer la búsqueda de purificación por parte de Alcméon que, sabemos por otras fuentes, buscó en la corte de Fegeo, rey de Psófide. El pedido a un rey extranjero de purificación es típico de los mitos griegos; así lo hace, por ejemplo, Belerofonte cuando se dirige a la corte del rey Preto en Tirinto, tras asesinar accidentalmente a un hombre en Corinto. Asimismo, contamos con un ejemplo trágico: en otra tragedia de Eurípides sobre la locura, Heracles, Teseo ofrece a Heracles la purificación, luego de que este último haya asesinado a su familia ${ }^{48}$.

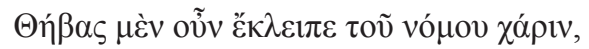

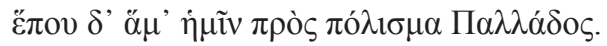

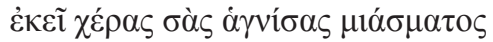

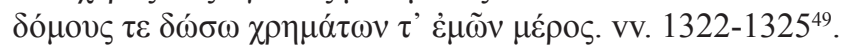

Por lo tanto, abandona Tebas en nombre de la ley, y acompáñanos a los edificios de la ciudad de Palas. Allí, después de que yo purifique tus manos de la mancha, te daré casas y parte de mis bienes.

\footnotetext{
47 Para un estudio general sobre la polución en el género trágico, véase Meinel (2015).

48 Véase Perczyk (2018a: 358-362), que analiza la contaminación por el crimen de los hijos y el ofrecimiento de purificación por parte de Teseo en Heracles de Eurípides.

49 Los pasajes citados de Heracles de Eurípides corresponden a la edición de Diggle (1981).
} 
Parker (1996 [1983]: 374) explica que en los mitos los hombres de riqueza, posición elevada y responsabilidad dentro de la comunidad, son los personajes encargados de ejecutar los rituales de purificación por homicidios. De hecho, en el fr. 72 Kannicht, transmitido por Suda ( $\pi 963$ Adler) y adjudicado a Alcmeón en Psófide,

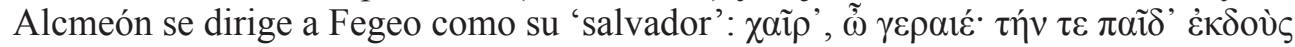

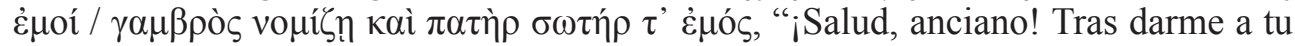
hija en matrimonio, te tengo por suegro, padre y salvador" ${ }^{50}$. Es importante destacar que el fragmento expresa la importancia de la dimensión humana en la recuperación, ya que un hombre es el encargado de llevar adelante el ritual de purificación ${ }^{51}$. Lo cierto es que la familia de palabras de $\sigma \tilde{\omega} \zeta$, a la que pertenece $\sigma \omega \tau \eta \dot{\rho} \rho$, se relaciona con la salvación y la salud.

Por último, el fr. 82 Kannicht, citado por Estobeo en su Antología (IV, 25, 15), sin explicitar a cuál de las dos tragedias de Eurípides sobre el matricida pertenece, destaca otra arista de la cuestión de la contaminación, que es su relación con el castigo

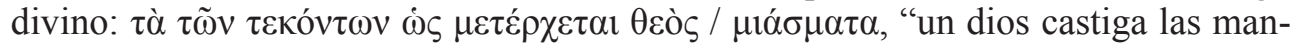
chas de (contra) los padres" ${ }^{52}$. El genitivo $\tau \varepsilon \kappa o ́ v \tau \omega v$ puede entenderse de dos modos diferentes: como un genitivo de propiedad, "de los padres", o como un genitivo objetivo, "contra los padres", en cuyo caso sería una alusión al crimen cometido contra ellos. Si se entiende que se trata de un genitivo de propiedad, el fragmento pertenecería a Alcmeón en Corinto en tanto remite a los hijos de un criminal y sería posible que sean los hijos de Alcmeón; pero si se lo considera como un genitivo objetivo, se lo podría ubicar en Alcmeón en Psófide, ya que aludiría al matricidio (Filócomo, en prensa). Me inclino por la idea de que el fragmento pertenece a Alcmeón en Psófide, en tanto en ninguna otra fuente conservada del mito el asesinato de Erífila tiene consecuencias para los descendientes de Alcmeón, lo cual constituye, como indiqué en el inicio del apartado anterior sobre Alcmeón y Orestes, la diferencia principal entre los dos matricidios.

Entonces, si bien no se han conservado fragmentos que indiquen la presencia de las Erinias, que por tratarse de las personificaciones de la venganza que perseguían a los culpables de crímenes intrafamiliares tenían un papel central en las representaciones teatrales sobre los asesinatos provocados por la locura, se han identificado en los tres fragmentos analizados los elementos esenciales acerca de la cuestión del míasma: la sangre, la búsqueda de purificación y el castigo divino.

\section{Conclusiones}

En el presente artículo he llevado adelante un estudio de las tragedias fragmentarias de Eurípides sobre Alcmeón centrado en el origen y las consecuencias de la enfermedad de la locura, en particular el matricidio y el míasma. El análisis permitió adjudicar fragmentos cuya atribución es dudosa y plantear que en Alcmeón en Psófide se escenificaba el segundo viaje. Se llevó adelante un estudio comparativo con Orestes, otra obra del mismo autor centrada en la manía, en la que también la enfermedad se

50 Jouan \& van Looy (2002 [1998]: 105) entienden que el primer verso se divide en dos versos conservados de forma incompleta.

51 Véase nota 2 del presente artículo.

52 Collard \& Cropp (2008: 97) destacan el hecho de que el $\mathrm{fr}$. $82 \mathrm{~K}$ parafrasea el encabezado del capítulo de Estobeo. 
presenta como castigo por un crimen cometido consciente y deliberadamente, que permitió identificó un rasgo común en los protagonistas de las dos tragedias, que es el aspecto lastimoso o deplorable como consecuencia de la locura. Se trata de un elemento que no encontramos en Heracles y Bacantes, tragedias en las que la locura les hace matar involuntariamente en dos casos, Heracles y Agave, y, en el caso de Penteo, es un castigo por prohibir el culto de Dioniso, donde la representación de la enfermedad se enfoca en un trastrocamiento de los papeles adjudicados a cada sexo. ${ }^{53}$

\section{Bibliografía}

Andrade, Nora (2007), Eurípides. Orestes, Buenos Aires, Losada.

Belfiore, Elizabeth (2000), Murder among Friends, Violation of Philia in Greek Tragedy, Oxford, Clarendon Press.

Bernabé, Alberto (1996 [1987]) (ed.), Poetae Epici Graeci, Testimonia et Fragmenta, pars I, Berlin, De Gruyter.

Bunker, Henry A. (1944), «Mother-Murder in Myth and Legend», The Psychoanalytic Quarterly 13: 198-207.

Bywater, Ingram (1963 [1894]), Aristotelis. Ethica Nicomachea, Oxford, Clarendon Press.

Caballero González, Manuel (2011), El personaje mítico de Atamante en las literaturas griega y latina, Madrid, Universidad Complutense, tesis de doctorado inédita (publicada en versión abreviada: Der Mythos des Athamas in der griechischen und lateinischen Literatur, Tübingen, Narr, 2017).

Calame, Claude (1977), Les choeurs des jeunes filles en Grèce archaïque, t. I. Roma, E. dell'Ateneo e Bizzarri.

Camps, William Anthony (1966) (ed.), Propertius. Elegies, t. II, Cambridge, University

Press.

Carpanelli, Francesco (2018), «Semele e Licurgo, morte e follia nel teatro eschileo», en L. Austa (ed.), The Forgotten Theatre, Mitologia, drammaturgia e tradizione del dramma frammentario Grecolatino, Alessandria, Edizioni dell'Orso: 2-44.

Collard, Chistopher \& Cropp, Martin (2008), Euripides Fragments, Aegeus-Meleager, t. VII, Cambridge (Mass.), Harvard University Press.

Collard, Chistopher, Cropp, Martin J. \& Gibert, John C. (2004) (eds.), Euripides, Selected Fragmentary Plays, t. II, Oxford, Aris \& Phillips.

53 En el caso del Anfitrionida, se representa un proceso de feminización de forma indirecta: una divinidad femenina provoca la enfermedad, Lŷssa (Heracles, vv. 863-866); el uso del grupo verbal de $\beta \alpha \kappa \chi \varepsilon v ́ \omega$, propio del culto a Dioniso, una práctica religiosa realizada principalmente por mujeres (Heracles, vv. 896-897, 966-967, 1085-1086, 1119, 1122 y 1142); para cometer el crimen Heracles emplea el arco, un arma vinculada en el pensamiento griego con los bárbaros que eran identificados con lo femenino en la Grecia antigua; el coro compara el asesinato de los hijos con crímenes perpetrados por mujeres, y por la vergüenza de haber asesinado a su familia (Heracles, vv. 1016-1087), y, por último, el héroe se cubre con un peplo, la vestimenta típica de mujer entre los griegos (Heracles, vv. 520, 627-628, 1159-1160, 1198, 1203-1204 y 1214-1215). En cuanto a los casos de locura en Bacantes, por un lado, se registra un proceso de feminización evidente en Penteo, ya que el personaje acepta llevar un atuendo de bacante por sugestión del extranjero, que lo conduce a ver una bacanal en el Citerón, y un dios masculino con rasgos femeninos se encarga de enloquecerlo (Bacantes, vv. 352-354, 821-836 y 913-918). Por otro lado, se advierte un cambio transformador en Ágave y sus compañeras, en tanto usurpan las dos actividades que en la cultura griega eran típicas de los hombres, la caza y la guerra (Bacantes, vv. 50-52, 114-119, 731-733, 751-758, 1132-1133, 1145,1197-1199, 1202-1207, 1233-1243 y 1253). Al respecto, véase Perczyk (2018a: 244-259 y 283-304). 
Collard, Christopher (2005), «Euripidean Fragmentary Plays: The Nature of Forces and their Effect on Reconstruction», en F. McHardy, J. Robson \& D. Harvey (eds.), Lost Dramas of Classical Athens: Greek Tragic Fragments, Exeter, University of Exeter Press: 49-62.

Collard, Christopher, Cropp, Martin J. \& Lee, Kevin H. (1995) (eds.), Euripides. Selected Fragmentary Plays, t. I, Oxford, Aris \& Phillips.

Conti Jiménez, Luz (2000), «Perturbaciones mentales en los poemas homéricos y en las tragedias de Sófocles y Eurípides», Myrtia 15: 35-50.

Damet, Aurélie (2012), La septième porte, Les conflits familiaux dans l'Athènes Classique, Paris, Publications de la Sorbonne.

Davies, Malcolm \& Finglass, Patrick J. (2014), Stesichorus, The Poems, Cambridge: University Press.

De Poli, Mattia (2018) «La scena di riconoscimento nelle tragedie frammentarie di Euripide», en L. Austa (ed.), The Forgotten Theatre, Mitologia, drammaturgia e tradizione del dramma frammentario Greco-latino, Alessandria, Edizioni dell'Orso, 137-165.

Delcourt, Marie (1959), Oreste et Alcméon. Étude sur la projection légendaire du matricide en Grèce, Paris, Les Belles Lettres.

Detienne, Marcel (2001), Apolo con el cuchillo en la mano, Una aproximación experimental al politeísmo griego, Madrid, Akal.

Di Benedetto, Vincenzo (1965), Euripidis Orestes, Firenze, La Nuova Italia.

Diggle, James (1981), Euripidis Fabulae, t. II, Oxford, Clarendon Press.

Diggle, James (1994), Euripidis Fabulae, t. III, Oxford, Clarendon Press.

Filippi, Marco (2018) «Frammenti di follia. Il tema della follia nella tragedia latina frammentaria», en L. Austa (ed.) The Forgotten Theatre, Mitologia, drammaturgia e tradizione del dramma frammentario Greco-latino, Alessandria, Edizioni dell'Orso: 285-305.

Filócomo, Constanza, «Un acercamiento a la locura del Alcmeón euripideo», en L. Gambon, (coord.) Un corpus olvidado. La tragedia fragmentaria y sus héroes, Bahía Blanca (en prensa).

Francisetti Brolin, Sonia (2013), «Sul mito tragico di Alcmeone: la mitologia politica di un secondo Oreste», Atti dell'Accademia delle Scienze di Torino. Classe di Scienze Morali, Storiche e Filologiche 147: 73-84.

Freixas, Alberto \& De Mundo, Sara Isabel (1950), Apolodoro, Biblioteca, Buenos Aires, Editorial de la Universidad.

Gantz, Timothy (1993) «Adrastos, Eriphyle, and Amphiaraos" y "Alkmaion and Eriphyle», en Early Greek Myth, A Guide to Literary and Artistic Sources, Baltimore, Johns Hopkins University Press: 506-509 y 525-528.

García Gual, Carlos (2014), La venganza de Alcmeón, Un mito olvidado. México D.F., Fondo de Cultura Económica.

González Ruz, María Gema (2013), Paradigmas de ingratitud. Ixión y Tántalo en las literaturas griega y latina, Madrid, Universidad Complutense, tesis de doctorado accesible en https://eprints.ucm.es/22386/1/T34655.pdf.

Guariglia, Osvaldo (1997), «Acciones voluntarias e involuntarias», en La Ética en Aristóteles o la Moral de la Virtud, Buenos Aires, Eudeba: 137-161.

Holmes, Brooke (2010), The Symptom and the Subject, Princeton, University Press.

Jouan, François \& van Looy, Herman (2002 [1998]), Euripide, t. VIII, 1er partie, Fragments de Aigeus à Autolykos, Paris. Les Belles Lettres.

Jouan, François (1990) «Les Corinthiens en Acarnanie et leurs prédécesseurs mythiques», en F. Jouan \& A. Motte (eds.), Mythe et politique, Actes du Colloque de Liège, 14-16 septiembre de 1989, Liège \& Paris, Les Belles Letres: 155-166. 
Kannicht, Richard (2004), Tragicorum Graecorum Fragmenta, t. V: Euripides, Göttingen, Vandenhoeck und Ruprecht.

Karamanou, Ioanna (2012), «Euripides" "Family Reunion Plays" and their Socio-Political Resonances», en A. Markantonatos \& B. Zimmermann (eds.), Crisis on Stage, Tragedy and Comedy in Late Fifth-Century Athens, Berlin, De Gruyter: 241-252.

Kassel, Rudolf (1965), Aristotelis De arte poetica liber, Oxford, Clarendon Press.

Legras, Léon (1905), Les légendes thébaines dans l'épopée et la tragédie grecques, Paris, Société nouvelle de librairie et d'édition.

Liddell, Henry George \& Scott, Robert (1996 [1843]), Greek-English Lexicon, Oxford, Clarendon Press.

Lloyd-Jones, Hugh \& Wilson, Nigel (1990), Sophoclis Fabulae. Oxford, Clarendon Press.

Lombardi, Gabriel \& Perczyk, Cecilia J. (2019), «El odio hacia la mujer como móvil de la tragedia en Orestes de Eurípides», Affectio Societatis 16.31: 125-147.

Loraux, Nicole (1993 [1984]), The Children of Athena, Athenian Ideas about Citizenship and the Division between the Sexes, Princeton, University Press.

Lucas de Dios, José María (1983) Sófocles, Fragmentos, Madrid, Gredos.

Lucas de Dios, José María (2008), Esquilo, Fragmentos, Testimonios, Madrid, Gredos.

Medda, Enrico (2011 [2001]), Euripide, Oreste, Milano, BUR.

Meinel, Fabian (2015), Pollution and Crisis in Greek Tragedy, Cambridge, University Press.

Merkelbach, Rienhold \& West, Martin L. (1967), Fragmenta Hesiodea, Oxford, Clarendon Press.

Musso, Olimpio \& Burlando, Annalaura (2009), Tragedie di Euripide, t. IV, Torino, Unione Tipografico-Editrice Torinese.

Nauck, August (1964 [1889²]), Tragicorum Graecorum Fragmenta, Hildesheim, G. Olms.

Oldfather, Charles Henry (1935), Diodorus Siculus, Library of History, books III-VIII, Cambridge (Mass.), Harvard University Press.

Olivieri, Oretta (2010), «La geografia mitica delle imprese di Alcmeone dalla poesia epica alla tragedia», en E. Cingano (ed.) Tra panellenismo e tradizioni locali: generi poetici storiografia, Alessandria, Edizioni dell'Orso: 299-314.

Olivieri, Oretta (2013) «Alcmeone, un eroe itinerante a Corinto: i frammenti dell'omonima tragedia di Euripide», en P. Angelini Bernardini (ed.), Corinto. Luogo di azione e luogo di racconto, Atti del Convegno Internazionale, Urbino, 23-25 de septiembre de 2009, PisaRoma, Edizioni dell'Ateneo: 157-168.

Padel, Ruth (2005 [1995]), A quien los dioses destruyen. Elementos de la locura griega y trágica, México D.F., Sexto Piso.

Page, Denys L. (1972) (ed.), Aeschyli Septem quae supersunt Tragoedias, Oxford, Clarendon Press.

Parker, Robert (1996 [1983]), Miasma. Pollution and Purification in Early Greek Religion, Oxford, Clarendon Press.

Perczyk, Cecilia J. (2017), «La enfermedad del héroe en Orestes de Eurípides a la luz de la relación entre tragedia y medicina hipocrática», Anales de Filología Clásica 30.2: 111127.

Perczyk, Cecilia J. (2018a), La locura en Heracles y Bacantes de Eurípides, Una lectura en el cruce entre la filología clásica y el psicoanálisis, Buenos Aires, Miño \& Dávila.

Perczyk, Cecilia J. (2018b), «Postración/excitación. Los polos de la enfermedad en Orestes de Eurípides», Quaderni Urbinati di Cultura Classica 120.3: 45-55.

Pimentel Álvarez, Julio (1990 [1980]), Marco Tulio Cicerón, Cuestiones académicas. México D.F., Universidad Nacional Autónoma. 
Polignac, F. (2010) «Deux figures d'errance: Alcméon et Amphilochos, fils d'Amphiaraos», en P. Carlier \& C. Lerouge-Cohen (eds.). Paysage et religion en Grece antique, Mélanges offerts a Madeleine Jost, Paris, De Boccard:165-173.

Radt, Stephan (1985), Tragicorum Graecorum Fragmenta, t. III: Aeschylus, Göttingen, Vandenhoeck \& Ruprecht.

Radt, Stephan (1999 [1975]), Tragicorum Graecorum Fragmenta, t. IV: Sophocles, Göttingen, Vandenhoeck \& Ruprecht.

Schadewaldt, Wolfang (1952), «Zu einem Florentiner Papyrusbruchstück aus dem “Alkmeon in Psophis" des Euripides», Hermes 80: 46-66.

Seaford, Richard (1995), Reciprocity and Ritual, Homer and Tragedy in the Developing CityState, Oxford, Clarendon Press.

Severyns, Albert (1928), Le cycle épique dans l'école d'Aristarque, Paris-Liège, VaillantCarmanne \& E. Champion.

Sinnot, Eduardo (2007), Aristóteles, Ética Nicomaquea, Buenos Aires, Colihue.

Spiro, Fridericus (1903), Pausanias, Graeciae Descriptio, t. I-III, Leipzig, Teubner.

Stuart Jones, Henry \& Powell, Johannes Enoch (1942), Thucydidis, Historiae, t. I, Oxford, Clarendon Press.

Tarrant, Richard J. (2004), P. Ovidi Nasonis, Metamorphoses, Oxford, University Press.

van Looy, Herman (1964), Zes verloren tragedies van Euripides, Brussel, Paleis der Academien.

Vernant, Jean-Pierre (1987 [1974]), Mito y sociedad en la Grecia antigua, Barcelona, Siglo XXI.

Webster, Thomas Bertram Lonsdale (1967), The Tragedies of Euripides, London, Methuen.

West, Martin L. (1987), Euripides, Orestes, Warminster, Aris \& Phillips.

Willink, Charles W. (1986), Euripides, Orestes, Oxford, Clarendon Press.

Zieliński, Tadeusz (1922), «Alcmeonis Corinthii fabula Euripidea», Mnemosyne, New Series 50.3: 305-327. 